\title{
The Role of Adolescents' and Their Parents' Temperament Types in Adolescents' Academic Emotions: A Goodness-of-Fit Approach
}

\author{
Pinja Lahdelma ${ }^{1} \cdot$ Maria Tolonen $^{1} \cdot$ Noona Kiuru $^{1} \cdot$ Riikka Hirvonen $^{2}$ (D)
}

Accepted: 10 October 2020 / Published online: 20 October 2020

(c) The Author(s) 2020

\begin{abstract}
Background Academic emotions (e.g., enjoyment of learning or anxiety) play a significant role in academic performance and educational choices. An important factor explaining academic emotions can be students' temperament and the goodness-of-fit between their temperament and their social environment, including parents.

Objective This study investigated the unique and interactive effects of early adolescents' and their parents' temperament types on adolescents' academic emotions in literacy and mathematics.

Method The participants in the study consisted of 690 adolescent-parent dyads. Parents rated their own and their adolescents' temperaments, and adolescents reported their positive and negative emotions in literacy and mathematics.

Results The results showed that adolescents' temperament type was significantly related to their negative emotions in both school subjects. Adolescents with an undercontrolled temperament reported more anger compared to adolescents with a resilient or overcontrolled temperament, and more anxiety, shame, and hopelessness compared to resilient adolescents. In addition, undercontrolled adolescents reported more boredom in mathematics than resilient or overcontrolled adolescents. The parents' temperament type was related to positive emotions. Adolescents of resilient parents reported greater pride in mathematics than adolescents of undercontrolled or overcontrolled parents and higher hope in mathematics than adolescents of overcontrolled parents. Finally, overcontrolled adolescents with a resilient or overcontrolled parent reported higher enjoyment of mathematics and literacy in comparison to overcontrolled adolescents with an undercontrolled parent.

Conclusions The findings of the study provide new knowledge about the role of temperament in the school context by showing that differences in temperamental reactivity and regulation relate to adolescents' academic emotions.
\end{abstract}

Keywords Academic emotions $\cdot$ Adolescence $\cdot$ Goodness-of-fit $\cdot$ Parents $\cdot$ Temperament

Pinja Lahdelma and Maria Tolonen contributed equally to this work.

Electronic supplementary material The online version of this article (https://doi.org/10.1007/s1056 6-020-09582-1) contains supplementary material, which is available to authorized users.

Extended author information available on the last page of the article 


\section{Introduction}

During adolescence, individuals need to face many physical and psychological changes and cope with new challenges and demands concerning their self-expression and self-regulation (Flook and Fuligni 2008; Yap et al. 2007). Adolescence has been linked to an increase in intense negative affect, which may expose adolescents to a heightened risk of psychopathology, such as depressive symptoms (Yap et al. 2007). Since school is a fundamental part of adolescents' lives, it is vital to investigate emotional experiences in this context. Academic emotions refer to emotions that arise in relation to achievement activities and outcomes, and play an important role in students' learning, academic performance, and educational paths (Pekrun 2006; Pekrun and Perry 2014). This study aimed to add understanding of individual differences that influence emotional reactions in the school context, and through this, to help identify and support students that are vulnerable to problems in school adjustment and learning. Because emotions may be influenced by temperamental differences in reactivity and self-regulation (Pekrun 2006), we focused on the unique and interactive effects of adolescent and parent temperaments. Both adolescent and parent temperaments were deemed essential because the goodness-of-fit (Thomas and Chess 1977) between their characteristics contributes to the interaction between adolescents and their parents. Research on spillover effects suggests that individuals' experiences in one context can influence experiences in another context, for example when conflicts and stress at home affect adolescents' moods, behaviour, and well-being at school (Flook and Fuligni 2008; Timmons and Margolin 2015). Presumably, adolescents' daily interactions with their parents influence their emotional experiences in the school context. We approached this interaction through the concept of temperament.

\section{Temperament}

Following Rothbart and colleagues' developmental model of temperament (Evans and Rothbart 2007; Rothbart et al. 2000), we conceptualized temperament as individual differences in reactivity and self-regulation, manifested in the different behavioural tendencies of the individuals. These differences are believed to result from a complex interplay between genetic, biological, and environmental factors influencing individual development already before birth and throughout life, as individuals interact with their environments (Rothbart et al. 2000; Shiner et al. 2012).

The developmental model of temperament defines four broader temperament dimensions (Evans and Rothbart 2007; Rothbart et al. 2001): effortful control, surgency/extraversion, negative affectivity, and for the fourth, affiliation for adolescents and orienting sensitivity for adults. Individuals high in effortful control have high activation control, attentional control, and inhibitory control. Activation control describes an individual's ability to perform an action despite a strong urge to avoid it, whereas inhibitory control has to do with the ability to suppress inappropriate behaviour (Evans and Rothbart 2007). Individuals high in surgency/extraversion are described as being high in sociability, enjoying intense stimuli, and being comfortable with new people and situations (Rothbart et al. 2001). In turn, individuals high in negative affectivity are defined as being prone to experiencing increased amounts of frustration, sadness, and discomfort when, for example, facing disappointments. The fourth temperament dimension is different for adolescents and adults. For adolescents, it is affiliation, or the desire to feel closeness with others. For 
adults, it is orienting sensitivity, which includes neutral and affective perceptual sensitivity and associative sensitivity (Evans and Rothbart 2007; Rothbart et al. 2001).

In the present study, we aimed to examine the interactive effects of adolescents' and parents' temperaments by utilising a person-centred approach (van Leeuwen et al. 2004). This approach aims to identify patterns of temperament dimensions within subgroups of individuals (see Rothbart and Bates 2007), and consequently, it enables a more in-depth examination of the interplay between parents' and adolescents' temperament types. Previous studies using a person-oriented approach have identified three distinct types of personality or temperament: resilient, undercontrolled, and overcontrolled (e.g., Asendorpf et al. 2001; van Leeuwen et al. 2004; see also Shiner et al. 2012). Resilient children and adolescents have been found to be well adjusted to school, for example, in terms of cognitive skills and academic performance (Asendorpf and van Aken 1999; Hart et al.2005; Robins et al. 1996), and low problem behaviour (Hirvonen et al. 2018). In contrast, the undercontrolled type has been connected to poor adaptation, such as poor academic performance, conduct disorders, and externalising problem behaviour (Asendorpf et al. 2001; Hart et al. 2005; Robins et al. 1996). The overcontrolled type has been associated with low self-esteem and internalising problems (Asendorpf and van Aken 1999; Robins et al. 1996; van Leeuwen et al. 2004) and in some studies also with lower achievement (Asendorpf and van Aken 1999; Hart et al. 2005).

\section{Associations Between Adolescent Temperament and Academic Emotions}

Academic emotions arise as students' responses to achievement activities and outcomes in academic settings (Pekrun 2006; Pekrun and Perry 2014). The control-value theory of academic emotions deals with the premises, situation specificity, consequences, regulation, and general nature of academic emotions (Pekrun et al. 2002; Pekrun and Perry 2014). The basis of the theory relies on the assumption that individuals' experiences of academic emotions arising in different learning and achievement situations depend on the extent to which they feel they are in control of the situation and the kind of subjective value they give to the situation and to the outcomes that may result.

According to the control-value theory, academic emotions can be described from three different perspectives (Pekrun 2006; Pekrun et al. 2002; Pekrun and Perry 2014). First, according to their object focus, emotions can be divided into prospective outcome (e.g., anticipatory joy), retrospective outcome (e.g., pride), or activity (e.g., boredom) emotions. Second, emotions can be grouped according to their valence, either as positive (e.g., hope) or negative (e.g., anxiety) emotions. Third, emotions can be physiologically and behaviourally activating, such as enjoyment or anger, or deactivating, such as relief or hopelessness (Pekrun 2006; Pekrun et al. 2002; Pekrun and Perry 2014). In the present study, our focus was on eight emotions that represent both positive and negative valence and both activating and deactivating types of emotions: three of the chosen activating emotions were positive (enjoyment, pride, hope), and three of them were negative (anxiety, anger, shame), whereas the two deactivating emotions were both negative (boredom, hopelessness).

It has been suggested that individual characteristics such as temperament or personality can have a significant impact on the experiences of academic emotions, because temperament forms the physiological basis for emotions that does not involve cognitive ability (see Pekrun 2006). Temperamental characteristics influence how students evaluate situations, how they react to them, and how they regulate their emotional reactions (Lengua and Long 2002; Thompson et al. 2014). Temperament can also affect certain cognitions; for example, 
shy and inhibited adolescents may be more prone to developing pessimistic attitudes concerning their future (Evans and Rothbart 2007). Consequently, temperament is expected to contribute to the form and threshold of emotional reactions in learning situations and affect the types of regulation methods that students use.

Negative correlations have been reported for extraversion with humiliation (shame) and anxiety among adolescents, indicating that students high in extraversion may be prone to experiencing less shame and anxiety in achievement situations (Soric et al. 2013). In addition, positive mood and approach behaviour, characteristics linked to extraversion, have been positively associated with a proactive strategy of emotion regulation (cognitive reappraisal) and negatively with a less adaptive regulation strategy (expressive suppression) of emotions (Jaffe et al. 2010). In contrast, Thompson et al. (2014) and Lengua and Long (2002) found that negative affectivity was related to showing an avoidant coping style and perceiving situations as threatening rather than challenging, suggesting that children and adolescents high in negative affectivity tend to experience situations more negatively and have less adaptive ways of coping with challenges. Moreover, negative affectivity has been linked to negative achievement emotions (Lehikoinen et al. 2019) as well as to increased adjustment problems, including anxiety and depressive symptoms (Lengua 2006; see also Yap et al. 2007). Finally, it has been suggested that good self-regulation skills (such as high effortful control) help students manage their emotional reactions effectively and use different coping styles in stress-evoking situations more flexibly (Lengua and Long 2002; Thompson et al. 2014). Consequently, effortful control has been found to correlate positively with positive achievement emotions and negatively with negative achievement emotions (Lehikoinen et al. 2019).

\section{The Goodness-of-Fit Between Adolescents' and Their Parents' Temperaments in Relation to Adolescents' Academic Emotions}

The concept of goodness-of-fit refers to the compatibility between an individual's temperament and their environment (Thomas and Chess 1977; see also Lerner and Lerner 1994; Shiner et al. 2012). Thomas and Chess emphasized that when the characteristics, expectations, and demands of the environment meet those of the child's, there is a "goodness-offit" that enables a child or adolescent's balanced development. In contrast, if there is no compatibility between the child and their environment, a "poorness-of-fit" may result. It should be borne in mind that as adolescents move from one developmental stage to the next and face new influences from new environments, the compatibility between the adolescent and the environment may also change (Lengua 2006; Thomas and Chess 1977).

Parents and adolescents and their temperaments mutually contribute to their interaction (Lengua 2006; Yap et al. 2007). The goodness or poorness of fit in their relationship is influenced by, for example, the extent to which the adolescent meets the parent's expectations and values, the parent's awareness and respect towards the adolescent's individual characteristics, and the parent's own temperament (Lerner and Lerner 1994; Thomas and Chess 1977). In childhood, the parents' role in the socialization of the child is significant: parents communicate about environmental demands, are in charge of routines, and act as moderators between the child and the outside world (Thomas and Chess 1977). In adolescence, the parents' role loses significance as adolescents seek more independence and increasingly establish relationships with other significant social groups, such as peers, teachers, and other adults (Yap et al. 2007). Nevertheless, the parent-adolescent relationship remains a significant factor in an adolescent's emotion expression and regulation. 
For example, the way parents respond to an adolescent's expression of negative emotions affects the adolescent's emotion regulation skills (Jaffe et al. 2010; Yap et al. 2007; see also Ramsden and Hubbard 2002). In addition, the parents' ability to discuss emotional experiences with the adolescent may affect the adolescent's ability to understand their own and other people's emotions (Jaffe et al. 2010; Yap et al. 2007).

In previous research, especially among children, a common approach to studying goodness-of-fit or temperament-environment interaction has been to study children's temperament and parenting (for reviews, see Kiff et al. 2011b; Rothbart and Bates 2007). Research on the interactive effects of child temperament and parenting suggest that children may be differentially susceptible to the quality of parenting, that is, certain characteristics may produce positive outcomes when in interaction with supportive parenting but lead to unfavourable outcomes when combined with inadequate or low-quality parenting (Jaffe et al. 2010; Lengua 2006; Rothbart and Bates 2007). For example, studies of children and early adolescents (ages 8-12) showed that children low in effortful control reported more depression and anxiety in the presence of poor-fitting parenting (Kiff et al. 2011a), and children high in fear and frustration showed more depressive symptoms when combined with negative parenting (Oldehinkel et al. 2006). There is less research on the goodness-of-fit between adolescents and parents in terms of the compatibility of their temperaments, but a few exceptions exist. For example, Rettew, Stanger, McKee, Doyle and Hudziak (2006) found that early adolescents' and their parents' temperaments had significant interactive effects on the adolescents' psychopathology (internalising and externalising problem behaviour and attention problems), over and above the effects of parents' and adolescents' individual temperaments. This indicates that merely observing the direct linear effects of adolescents' and parents' temperaments was not enough without considering the interaction between them. Similarly, Hirvonen and colleagues (2018) found that early adolescents generally reported higher socioemotional functioning if their temperament profiles were similar to their mothers' temperament profiles, suggesting that the resemblance of adolescent and parent temperaments may create a fruitful environment for adaptive socioemotional development.

Although there is a lack of previous research on the goodness-of-fit between adolescents' and their parents' temperaments in relation to adolescents' emotions in the school context, there is reason to assume that the interaction between adolescents' and parents' temperaments can contribute to adolescents' expression of these emotions. In his control-value theory, Pekrun (2006) suggests that students' social surroundings, including their parents, have a significant effect on students' academic emotions by shaping their learning environment. Parents contribute to this environment by supporting adolescents' learning, providing them with opportunities, and expressing their own expectations and values in learning to the adolescents. It is the interaction between this learning environment and adolescents' own characteristics, expectations, and values that is assumed to further result in adolescents' emotional reactions in learning situations (Pekrun 2006). We can further expect that the interaction is affected by the temperamental characteristics of both the adolescent and the parent, that is, their way of reacting and expressing themselves and responding to each other's reactions (see Yap et al. 2007).

\section{Research Questions and Hypotheses}

Our first research aim was to examine the extent to which adolescents' temperament types are related to their academic emotions in literacy and mathematics. In general, we expected 
resilient adolescents to report a higher level of positive emotions and a lower level of negative emotions than under- and overcontrolled adolescents because of their better self-regulation abilities and low negative emotionality (Lehikoinen et al. 2019; Lengua 2006; Lengua and Long 2002; Thompson et al. 2014). We expected undercontrolled adolescents to report a particularly high level of negative emotions because of their high negative affectivity and low self-regulation skills (Lehikoinen et al. 2019; Lengua and Long 2002; Thompson et al. 2014). Finally, we expected overcontrolled adolescents to report a relatively high level of negative emotions, especially deactivating negative emotions of anxiety, boredom, and hopelessness, because their low extraversion and relatively high level of self-regulation can expose them to internalising problems (Asendorpf and van Aken 1999; Robins et al. 1996; van Leeuwen et al. 2004).

Our second aim was to examine how the parents' temperament type alone and in interaction with the adolescents' temperament type contributes to the adolescents' academic emotions. Because previous research on this topic is lacking, we did not set specific hypotheses for the unique and interactive effects of parents' temperament. However, following the idea that goodness-of-fit between adolescents and their environments supports adaptive development (Lerner and Lerner 1994; Thomas and Chess 1977), we expected adolescents with different types of temperament to report different levels of emotions depending on their parents' temperament type.

In all analyses, we controlled for the effects of student gender and academic performance. Gender differences in academic emotions have been reported among high-school students (Soric et al. 2013) and university students (Pekrun, Goetz, Frenzel, Barchfeld, and Perry 2011), suggesting that male students have a tendency to report higher levels of negative academic emotions and lower levels of positive emotions than female students, with the exception of anxiety, for which female students report levels higher than or equal to male students.

\section{Method}

\section{Participants and Procedure}

The sample was part of a larger longitudinal study (Ahonen and Kiuru 2013-2017) and consisted of 690 early adolescents ( 381 or $55.2 \%$ girls, 309 boys) from 57 classes. Because five of the classes were combined classes with fifth- and sixth-graders studying together, 18 of the participants were fifth-graders and the remaining 672 students were sixth-graders. The participants were recruited from one large town and one middle-sized town in Central Finland. The mean age of the adolescents was 12.3 years $(S D=0.4)$. A total of $96.7 \%$ of the adolescents had Finnish as their mother tongue, 1.6\% were bilingual (Finnish and another language), and $1.4 \%$ spoke a language other than Finnish. The mother tongue was not known for $0.3 \%$ of the participants. This corresponds to the demographics of the Finnish population (Official Statistics of Finland 2020) as 3.6\% of the population outside the Helsinki metropolitan area were foreign-language speakers and $3.7 \%$ had a foreign background at the time of the present study. Data on the adolescents were collected in autumn 2014 in the classrooms during regular school days by two trained testers.

The parents were asked to rate their own and their adolescents' temperaments. The data were collected through questionnaires that were sent to the parents by electronic or regular mail in autumn 2014. If both parents participated, responses from only one of them 
(primarily mothers) were included in the present sample. Of the respondents, $650(95.3 \%)$ were mothers, $26(3.8 \%)$ fathers, and six $(0.8 \%)$ others (e.g., stepparents or other guardians). The parents' age range was 29 to 64 years with a mean of 42.0 years $(S D=5.6)$.

A total of $76.1 \%$ of the families were nuclear families, $12.2 \%$ were single-parent families, $10.0 \%$ were blended families, and $1.8 \%$ were other types of families. A total of $3.8 \%$ of the participating parents were not educated beyond nine years of basic education, $29.3 \%$ had completed upper-secondary education, $40.1 \%$ had a bachelor or vocational college degree, and $26.8 \%$ had a master's degree or higher. The sample was fairly representative of the Finnish population (Official Statistics of Finland 2018a, b), with the exceptions of two-parent households and parents with a bachelor's degree or higher being slightly overrepresented.

Parents' informed consent and child assent were required for their participation in the study. Teachers of the participating classes also gave their written consent for the data collections to be conducted during school days. The larger longitudinal study has been evaluated and approved by the ethics committee of the local university. The authors state that there is no conflict of interest.

\section{Measures}

Adolescents' temperament The parents rated their adolescents' temperament using the short version of the Early Adolescent Temperament Questionnaire - Revised (EATQ-R; Capaldi and Rothbart 1992; Ellis and Rothbart 2001; Finnish translation by Katri Räikkönen-Talvitie). The scale consists of 62 statements assessed on a five-point Likert scale $(1=$ almost never true; $5=$ almost always true $)$. The statements measure the four temperamental dimensions of effortful control, negative affectivity, surgency/extraversion, and affiliation. Each of the scales further consists of subscales (activation control, attentional control, and inhibitory control for effortful control; frustration, sadness, and fear for negative affectivity; high intensity pleasure and shyness (reversed) for surgency/extraversion; and affiliation as the only subscale for affiliation). The affiliation scale was not used in the present study because we wanted to focus on the three temperament dimensions that are fairly similar between the adolescent and parent scales. The mean scores for effortful control (18 items), negative affectivity (16 items), and surgency/extraversion (14 items) were calculated. The Cronbach's alpha reliabilities for the scales were $0.90,0.84$, and 0.83 , respectively.

Adolescents' scores in effortful control, negative affectivity, and surgency/extraversion were standardised to make sure that when conducting cluster analysis for the temperament types, differences in standard deviations would not affect distances in forming the clusters. Following this, outliers that were outside 2.5 standard deviations of the mean were detected and recoded into the values of -2.5 (for unusually small outliers) or +2.5 (for unusually large outliers). A $K$-means cluster analysis was then conducted using the standardised scores of effortful control, negative affectivity, and surgency/ extraversion. Following a theoretical assumption of the resilient, undercontrolled, and overcontrolled types, a three-cluster solution was chosen. A cross-validation procedure (Mandara 2003) using two randomly divided subsamples was replicated 10 times, resulting in an almost perfect agreement (mean of Cohen's kappa $=0.84$ ) for the three-cluster solution. The average silhouette score for the solution was 0.29 , which was higher than for the alternative four- and five-cluster solutions ( 0.26 and 0.26 , respectively) but lower than for the two-cluster solution (0.32). In the final three-cluster solution, the first 
cluster $(n=257 ; 38.0 \%)$, which was characterised by higher-than-average scores for effortful control $(z$ score $=0.67)$ and surgency/extraversion $(z$ score $=0.63)$ and a belowaverage score in negative affectivity $(z$ score $=-0.85)$, was labelled the resilient group. The second cluster $(n=206 ; 30.5 \%)$, with an above-average score in negative affectivity $(z$ score $=0.93)$, an average score in surgency/extraversion $(z$ score $=0.22)$, and a belowaverage score in effortful control $(z$ score $=-1.03)$, was named the undercontrolled group. The third cluster $(n=213 ; 31.5 \%)$, with average scores in effortful control $(z$ score $=0.20)$ and negative affectivity $(z$ score $=0.12)$ and a below-average score in surgency/extraversion $(z$ score $=-0.97$ ), was labelled the overcontrolled group. The cluster sizes were sufficient and relatively similar for all three clusters. Based on analyses of variance, the clusters significantly differed from each other in effortful control, negative affectivity, and extraversion ( $p s<0.001$ in all post hoc pairwise comparisons using the Bonferroni test).

Parents' temperament The parents rated their own temperament using a short form of the Adult Temperament Questionnaire-Revised (ATQ-R; Evans and Rothbart 2007; Finnish translation by Katri Räikkönen-Talvitie). The short version consists of 77 statements assessed on a seven-point Likert scale $(1=$ fits me very poorly; $7=$ fits me very well $)$. The statements measure the four temperament dimensions of effortful control, negative affectivity, surgency/extraversion, and orienting sensitivity. These scales further consist of subscales (activation control, attentional control, and inhibitory control for effortful control; fear, frustration, sadness, and discomfort for negative affectivity; sociability, high intensity pleasure, and positive affect for surgency/extraversion; and neutral perceptual sensitivity, affective perceptual sensitivity, and associative sensitivity for orienting sensitivity). The orienting sensitivity scale was not used in the present study to be consistent with the adolescent temperament scale. The mean scores for effortful control (19 items), negative affectivity (26 items), and surgency/extraversion (17 items) were calculated. The Cronbach's alpha reliabilities for the scales were $0.81,0.85$, and 0.75 , respectively.

Similar to the procedure with the adolescents' temperament measure, the parents' scores in effortful control, negative affectivity, and surgency/extraversion were standardised, and outliers that exceeded the standardised scores -2.5 or 2.5 were detected and recoded into the values of -2.5 or +2.5 . A $K$-means cluster analysis with three clusters was conducted. A cross-validation procedure (Mandara 2003) with 10 replications produced a substantial agreement (mean of Cohen's kappa $=0.73$ ) for the three-cluster solution. The average silhouette score for the solution was 0.28 , which was higher than for the four- and five-cluster solutions ( 0.26 and 0.25 , respectively) but lower than for the two-cluster solution $(0.32)$. In the final three-cluster solution, the first cluster $(n=287 ; 42.0 \%)$ was characterised by an above-average score in effortful control (standardised score $z=0.78$ ), an average score in surgency/extraversion $(z$ score $=0.48$ ), and a below-average score in negative affectivity $(z$ score $=-0.79)$. It was labelled the resilient group. The second cluster $(n=203$; $29.7 \%$, with average scores in surgency/extraversion $(z$ score $=0.42)$ and negative affectivity $(z$ score $=0.44)$ and a below-average score in effortful control $(z$ score $=-0.74)$, was named the undercontrolled group. Finally, a cluster $(n=193 ; 28.3 \%)$ with a higher-thanaverage score in negative affectivity $(z$ score $=0.69)$, an average score in effortful control $(z$ score $=-0.36)$, and a below-average score in surgency/extraversion $(z$ score $=-1.14)$ was labelled the overcontrolled group. Cluster sizes were sufficient and relatively similar for all three clusters. Based on analyses of variance, the three clusters significantly differed from each other in effortful control and negative affectivity $(p s<0.01$ in all post hoc pairwise comparisons using Tamhane's T2 for effortful control and Bonferroni test for negative affectivity). In surgency/extraversion, the resilient and undercontrolled groups scored 
higher than the overcontrolled group ( $p$ 's $<0.001$ using Tamhane's T2), but there was no significant difference between the resilient and undercontrolled groups $(p=0.75)$.

Adolescents' academic emotions Adolescents rated their academic emotions in literacy and mathematics using a short version of the Achievement Emotions Questionnaire (AEQ; Pekrun et al. 2002 2011). The scale consisted of 24 items divided into three 8-item sections: learning-related emotions (e.g., "Studying makes me irritated"), class-related emotions (e.g., "I enjoy being in class"), and test-related emotions (e.g., "I'm proud of how well I mastered the exam"). The items measure nine academic emotions: enjoyment, hope, pride, anger, anxiety, shame, and hopelessness (three items for each), boredom (two items), and relief (one item). The students were asked to evaluate the same set of 24 items concerning their emotions in literacy and in mathematics using a five-point Likert scale $(1=$ disagree; $5=$ agree . In the present study, the one-item relief was not included. For the eight other emotions, composite scores were created separately in literacy and in mathematics by calculating a mean across the respective items. Cronbach alpha reliabilities for enjoyment, pride, hope, anger, hopelessness, anxiety, shame, and boredom were $0.73,0.78,0.76,0.56$, $0.77,0.62,0.68$, and 0.76 in literacy, and $0.75,0.80,0.77,0.54,0.74,0.62,0.67$, and 0.75 in mathematics, respectively.

Control variables To be used as a control variable in the analyses, adolescents' gender was coded as $1=$ girl and $2=$ boy. Adolescents' self-reported grades in literacy and mathematics at the end of grade 5 were also used as control variables. Grades in literacy ranged from 6 to 10 (on a scale from 4 to 10$)$ with a mean of $8.35(S D=0.81)$. Grades in mathematics ranged from 5 to 10 with a mean of $8.28(S D=0.95)$. There was $6.09 \%$ missing data in literacy grades and $5.51 \%$ in math grades.

\section{Statistical Analyses}

The first research question concerning the extent to which adolescents' temperament type was related to their academic emotions in literacy and mathematics was analysed using analysis of covariance (ANCOVA), controlling for gender and self-reported grade in literacy or mathematics as covariates. The second research question on the extent to which parents' temperament type uniquely and in interaction with adolescents' temperament type contributed to adolescents' academic emotions in literacy and mathematics was also analysed using ANCOVAs. The models included the main effects of adolescents' and parents' temperament types, as well as their interaction effect (adolescent type $\times$ parent type). The control variables, adolescents' gender and adolescents' grade in literacy or mathematics, were included in the ANCOVA models as covariates. In both research questions, the analyses were run separately for each emotion in literacy and mathematics. ${ }^{1}$ All analyses were conducted using IBM SPSS Statistics 24 software. Bivariate correlations between the study variables are presented in Table 1.

\footnotetext{
1 An alternative approach for studying the role of temperament in academic emotions would be to examine their linear relationship using continuous variables of the temperament dimensions. For interested readers, we provide the results of this variable-oriented approach in electronic supplementary material.
} 


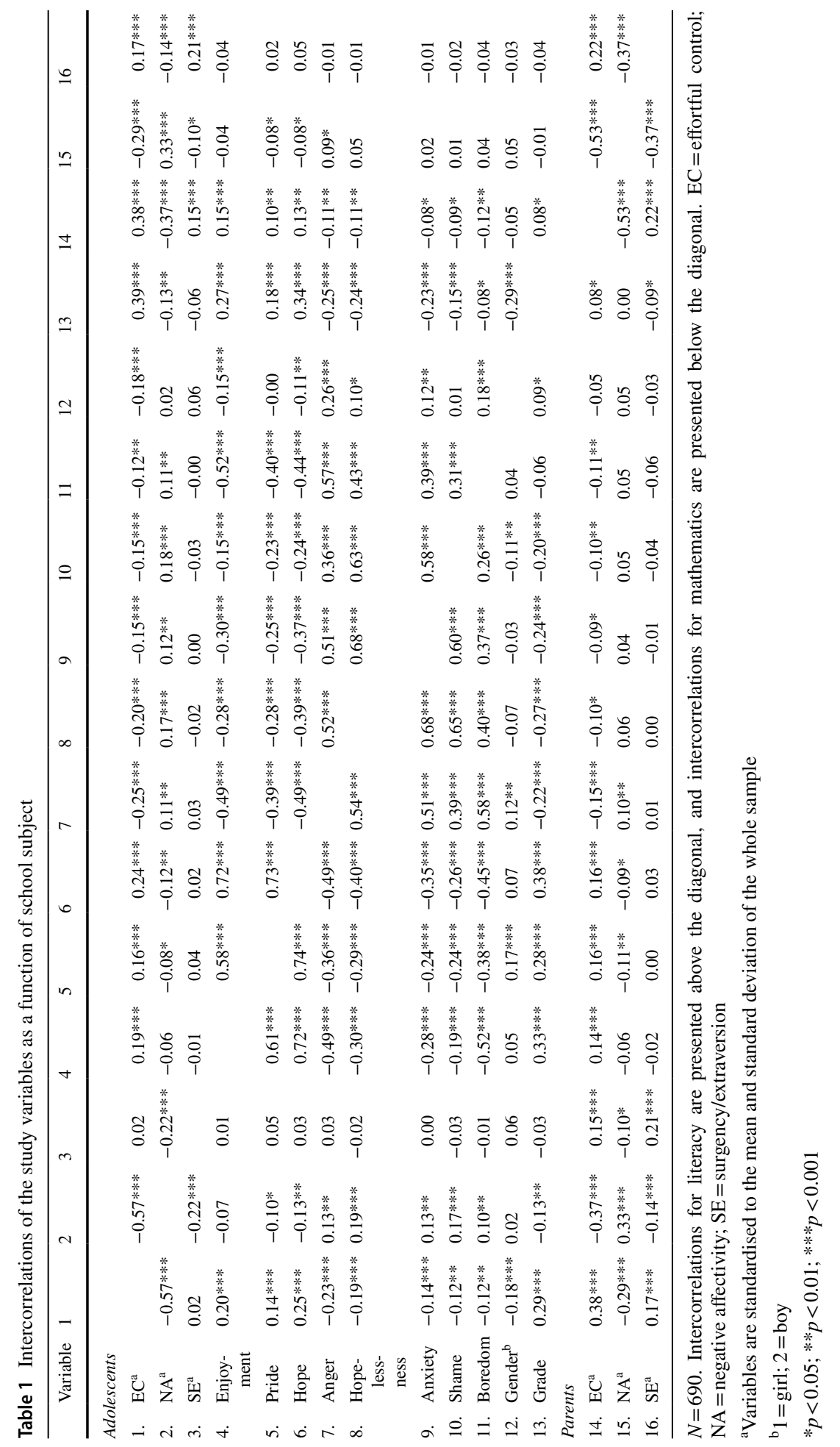


Table 2 Means and standard deviations for academic emotions in literacy by adolescent temperament type

\begin{tabular}{|c|c|c|c|}
\hline \multirow[b]{3}{*}{ Emotions } & \multicolumn{3}{|c|}{ Adolescent temperament } \\
\hline & $\begin{array}{l}\text { Resilient } \\
n=248\end{array}$ & $\begin{array}{l}\text { Undercontrolled } \\
n=186\end{array}$ & $\begin{array}{l}\text { Overcontrolled } \\
n=201\end{array}$ \\
\hline & $\mathrm{M}(\mathrm{SD})$ & $\mathrm{M}(\mathrm{SD})$ & $\mathrm{M}(\mathrm{SD})$ \\
\hline Enjoyment & $\begin{array}{l}3.24^{\mathrm{a}} \\
(0.83)\end{array}$ & $\begin{array}{l}3.01^{\mathrm{a}} \\
(0.83)\end{array}$ & $\begin{array}{l}3.13^{\mathrm{a}} \\
(0.81)\end{array}$ \\
\hline Pride & $\begin{array}{l}3.62^{\mathrm{a}} \\
(0.81)\end{array}$ & $\begin{array}{l}3.48^{\mathrm{a}} \\
(0.86)\end{array}$ & $\begin{array}{l}3.59^{\mathrm{a}} \\
(0.87)\end{array}$ \\
\hline Hope & $\begin{array}{l}3.82^{\mathrm{a}} \\
(0.77)\end{array}$ & $\begin{array}{l}3.54^{\mathrm{a}} \\
(0.78)\end{array}$ & $\begin{array}{l}3.68^{\mathrm{a}} \\
(0.80)\end{array}$ \\
\hline Anger & $\begin{array}{l}1.60^{\mathrm{a}} \\
(0.55)\end{array}$ & $\begin{array}{l}1.87^{\mathrm{b}} \\
(0.76)\end{array}$ & $\begin{array}{l}1.62^{\mathrm{a}} \\
(0.59)\end{array}$ \\
\hline Anxiety & $\begin{array}{l}1.70^{\mathrm{a}} \\
(0.69)\end{array}$ & $\begin{array}{l}1.99^{\mathrm{b}} \\
(0.85)\end{array}$ & $\begin{array}{l}1.82^{\mathrm{a}, \mathrm{b}} \\
(0.75)\end{array}$ \\
\hline Shame & $\begin{array}{l}1.59^{\mathrm{a}} \\
(0.73)\end{array}$ & $\begin{array}{l}1.93^{\mathrm{b}} \\
(0.89)\end{array}$ & $\begin{array}{l}1.71^{\mathrm{a}, \mathrm{b}} \\
(0.75)\end{array}$ \\
\hline Boredom & $\begin{array}{l}1.99^{\mathrm{a}} \\
(0.94)\end{array}$ & $\begin{array}{l}2.22^{\mathrm{a}} \\
(1.06)\end{array}$ & $\begin{array}{l}2.09^{\mathrm{a}} \\
(1.04)\end{array}$ \\
\hline Hopelessness & $\begin{array}{l}1.47^{\mathrm{a}} \\
(0.64)\end{array}$ & $\begin{array}{l}1.84^{\mathrm{b}} \\
(0.88)\end{array}$ & $\begin{array}{l}1.59^{\mathrm{a}, \mathrm{b}} \\
(0.72)\end{array}$ \\
\hline
\end{tabular}

Means within a row sharing the same superscripts are not significantly different at the level of $p<0.05$ (Bonferroni adjustment used)

\section{Results}

\section{Adolescents' Temperament Type and Academic Emotions in Literacy and Mathematics}

Our first aim was to investigate to what extent adolescents' temperament type was related to their academic emotions in literacy and mathematics, controlling for gender and previous grade in the respective subject. The means and standard deviations in academic emotions for adolescents' temperament types are presented in Table 2 for literacy and in Table 3 for mathematics.

The findings for literacy showed that adolescents' temperament type significantly explained their anger $\left(F(2,634)=5.47, p=0.004\right.$, partial $\left.\eta^{2}=0.02\right)$, anxiety $(F(2$, $635)=3.71, p=0.03$, partial $\left.\eta^{2}=0.01\right)$, shame $(F(2,633)=7.04, p<0.001$, partial $\left.\eta^{2}=0.02\right)$, and hopelessness $\left(F(2,633)=7.11, p<0.001\right.$, partial $\left.\eta^{2}=0.02\right)$ in literacy. Adolescents with an undercontrolled temperament reported significantly higher anger than adolescents with a resilient or overcontrolled temperament, and they also reported significantly more anxiety, shame, and hopelessness compared to the resilient adolescents. There were no significant differences between the temperament types in enjoyment, hope, pride, or boredom.

The results for mathematics (Table 3) showed that temperament type significantly explained adolescents' anger $\left(F(2,634)=7.16, p<0.001\right.$, partial $\left.\eta^{2}=0.02\right)$, anxiety $\left(F(2,634)=6.10, p=0.002\right.$, partial $\left.\eta^{2}=0.02\right)$, shame $(F(2,633)=4.92, p=0.008$, partial $\left.\eta^{2}=0.02\right)$, boredom $\left(F(2,633)=5.46, p=0.004\right.$, partial $\left.\eta^{2}=0.02\right)$, and hopelessness $\left(F(2,634)=8.51, p<0.001\right.$, partial $\left.\eta^{2}=0.03\right)$ in mathematics. Adolescents with an 
Table 3 Means and standard deviations for academic emotions in mathematics by adolescent temperament type

\begin{tabular}{llll}
\hline & \multicolumn{2}{l}{ Adolescent temperament } \\
\cline { 2 - 4 } & $\begin{array}{l}\text { Resilient } \\
n=250\end{array}$ & $\begin{array}{l}\text { Undercontrolled } \\
n=183\end{array}$ & $\begin{array}{l}\text { Overcontrolled } \\
n=201\end{array}$ \\
Emotions & $\mathrm{M}(\mathrm{SD})$ & $\mathrm{M}(\mathrm{SD})$ & $\mathrm{M}(\mathrm{SD})$ \\
\hline Enjoyment & $3.40^{\mathrm{a}}$ & $3.15^{\mathrm{a}}$ & $3.35^{\mathrm{a}}$ \\
& $(0.90)$ & $(0.98)$ & $(0.94)$ \\
Pride & $3.67^{\mathrm{a}}$ & $3.55^{\mathrm{a}}$ & $3.64^{\mathrm{a}}$ \\
& $(0.85)$ & $(0.92)$ & $(0.94)$ \\
Hope & $3.90^{\mathrm{a}}$ & $3.61^{\mathrm{a}}$ & $3.79^{\mathrm{a}}$ \\
& $(0.80)$ & $(0.84)$ & $(0.80)$ \\
Anger & $1.54^{\mathrm{a}}$ & $1.83^{\mathrm{b}}$ & $1.58^{\mathrm{a}}$ \\
& $(0.52)$ & $(0.70)$ & $(0.59)$ \\
Anxiety & $1.69^{\mathrm{a}}$ & $2.02^{\mathrm{b}}$ & $1.80^{\mathrm{a}, \mathrm{b}}$ \\
& $(0.67)$ & $(0.91)$ & $(0.73)$ \\
Shame & $1.63^{\mathrm{a}}$ & $1.93^{\mathrm{b}}$ & $1.74^{\mathrm{a}, \mathrm{b}}$ \\
& $(0.76)$ & $(0.90)$ & $(0.76)$ \\
Boredom & $1.87^{\mathrm{a}}$ & $2.20^{\mathrm{b}}$ & $1.92^{\mathrm{a}}$ \\
\multirow{2}{*}{ Hopelessness } & $(0.92)$ & $(1.09)$ & $(0.98)$ \\
& $1.48^{\mathrm{a}}$ & $1.84^{\mathrm{b}}$ & $1.59^{\mathrm{a}, \mathrm{b}}$ \\
& $(0.64)$ & $(0.87)$ & $(0.68)$ \\
\hline
\end{tabular}

Means within a row sharing the same superscripts are not significantly different at the level of $p<0.05$ (Bonferroni adjustment used)

undercontrolled temperament reported significantly higher anger and boredom in mathematics compared to adolescents with resilient or overcontrolled temperaments, and they also reported significantly higher anxiety, shame, and hopelessness in comparison with the resilient adolescents. There were no significant differences between the temperament types in any of the positive emotions.

\section{The Interactive Effects of Adolescents' and Their Parents' Temperament Types on Adolescents' Academic Emotions}

Our second aim was to examine the unique and interactive effects of adolescents' and their parents' temperament types on adolescents' emotions in literacy and mathematics, controlling for the effects of gender and grade in the respective subject. The results are presented in Table 4 for literacy and Table 5 for mathematics.

The results for literacy (Table 4) showed that adolescents' and parents' temperaments had a marginally significant $(p=0.07)$ interactive effect on adolescents' feelings of enjoyment. Consequently, ANCOVAs were run separately for each type of adolescent temperament to examine the effect of parent temperament on adolescents' enjoyment in literacy. The results showed that parents' temperament significantly explained feelings of enjoyment among adolescents with an overcontrolled temperament: overcontrolled adolescents with an undercontrolled parent reported less enjoyment than overcontrolled adolescents with a resilient or overcontrolled parent. In contrast, parents' temperament had no significant effect on enjoyment among adolescents with a resilient or undercontrolled temperament. Parents' temperament had no main or interactive effects with adolescents' temperament on any other emotions in literacy. 


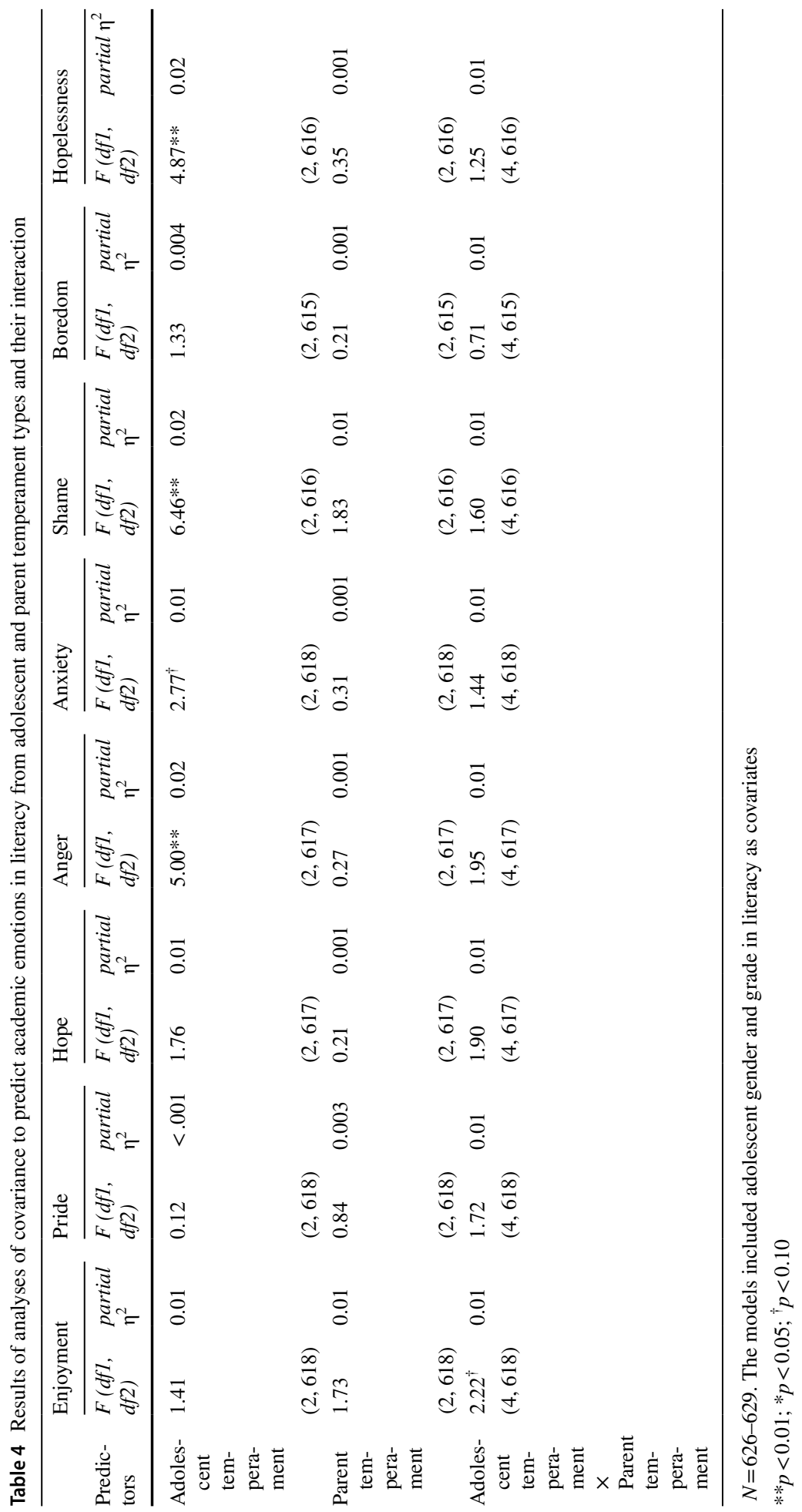


The results for mathematics (Table 5) showed a significant interactive effect between adolescent and parent temperament types on adolescents' enjoyment in mathematics. Further investigation of this interaction showed that parents' temperament had an effect on enjoyment for adolescents with an overcontrolled temperament: overcontrolled adolescents with an undercontrolled parent reported less enjoyment in mathematics compared to overcontrolled adolescents with a resilient parent. Parents' temperament had no effect on math enjoyment among adolescents with a resilient or undercontrolled temperament.

The results further showed that parents' temperament had a significant main effect on adolescents' pride in mathematics: adolescents who had a parent with a resilient temperament reported significantly higher pride in mathematics than adolescents whose parent had an undercontrolled or overcontrolled temperament. Additionally, a marginally significant $(p=0.05)$ main effect for parents' temperament type was found in adolescents' hope in mathematics: adolescents whose parent had a resilient temperament reported more hope in mathematics in comparison with adolescents whose parent had an overcontrolled temperament.

In anger, anxiety, boredom, shame, and hopelessness in mathematics, parents' temperament had no main or interactive effects with adolescent temperament.

\section{Additional Analyses: The Moderating Roles of Gender and Grade}

As additional analyses, we examined whether gender and grades in literacy and mathematics moderated the effects of adolescents' and parents' temperaments on academic emotions. The results showed, first, that adolescent gender had a small interactive effect on math hope $\left(p=0.048\right.$, partial $\left.\eta^{2}=0.01\right)$ : resilient boys reported higher hope in mathematics than boys with an undercontrolled temperament, whereas temperament had no effect on girls' hope in mathematics. Gender did not moderate any of the other effects of adolescent or parent temperament on academic emotions in literacy or mathematics.

The results further showed that grade in literacy had interactive effects with adolescent temperament on their pride $\left(p=0.003\right.$, partial $\left.\eta^{2}=0.02\right)$, hope $\left(p=0.04\right.$, partial $\left.\eta^{2}=0.01\right)$, and shame $\left(p=0.02\right.$, partial $\left.\eta^{2}=0.01\right)$ in literacy: High-performing (one SD above the group mean in literacy grade) adolescents with a resilient temperament reported higher pride and hope than high-performing adolescents with an overcontrolled temperament. In contrast, low-performing (one SD below the mean) adolescents reported higher shame if they had an undercontrolled temperament than if they had an overcontrolled or resilient temperament. Grade in literacy also had interactive effects with parents' temperament on adolescents' pride $\left(p=0.01\right.$, partial $\left.\eta^{2}=0.01\right)$ and hope $\left(p=0.001\right.$, partial $\left.\eta^{2}=0.02\right)$ in literacy: low-performing (one SD below the group mean) adolescents reported higher pride and hope if they had a resilient parent than if they had a parent with an overcontrolled temperament. No interaction effects were found in enjoyment, anger, hopelessness, anxiety, or boredom in literacy.

Finally, grade in mathematics had interactive effects with parents' temperament type on adolescents' enjoyment $\left(p=0.02\right.$, partial $\left.\eta^{2}=0.01\right)$, pride $\left(p=0.01\right.$, partial $\left.\eta^{2}=0.02\right)$, and hope $\left(p=0.03\right.$, partial $\left.\eta^{2}=0.01\right)$ in mathematics: adolescents with a poor grade in mathematics (one SD below the group mean) reported higher enjoyment, pride, and hope if they had a parent with a resilient temperament than if their parent had an undercontrolled or overcontrolled temperament. In math shame $\left(p=0.01\right.$, partial $\left.\eta^{2}=0.02\right)$ and hopelessness $\left(p=0.02\right.$, partial $\left.\eta^{2}=0.02\right)$, three-way interaction effects between math grade, adolescent temperament, and parent temperament were found: High-performing (one SD above the 


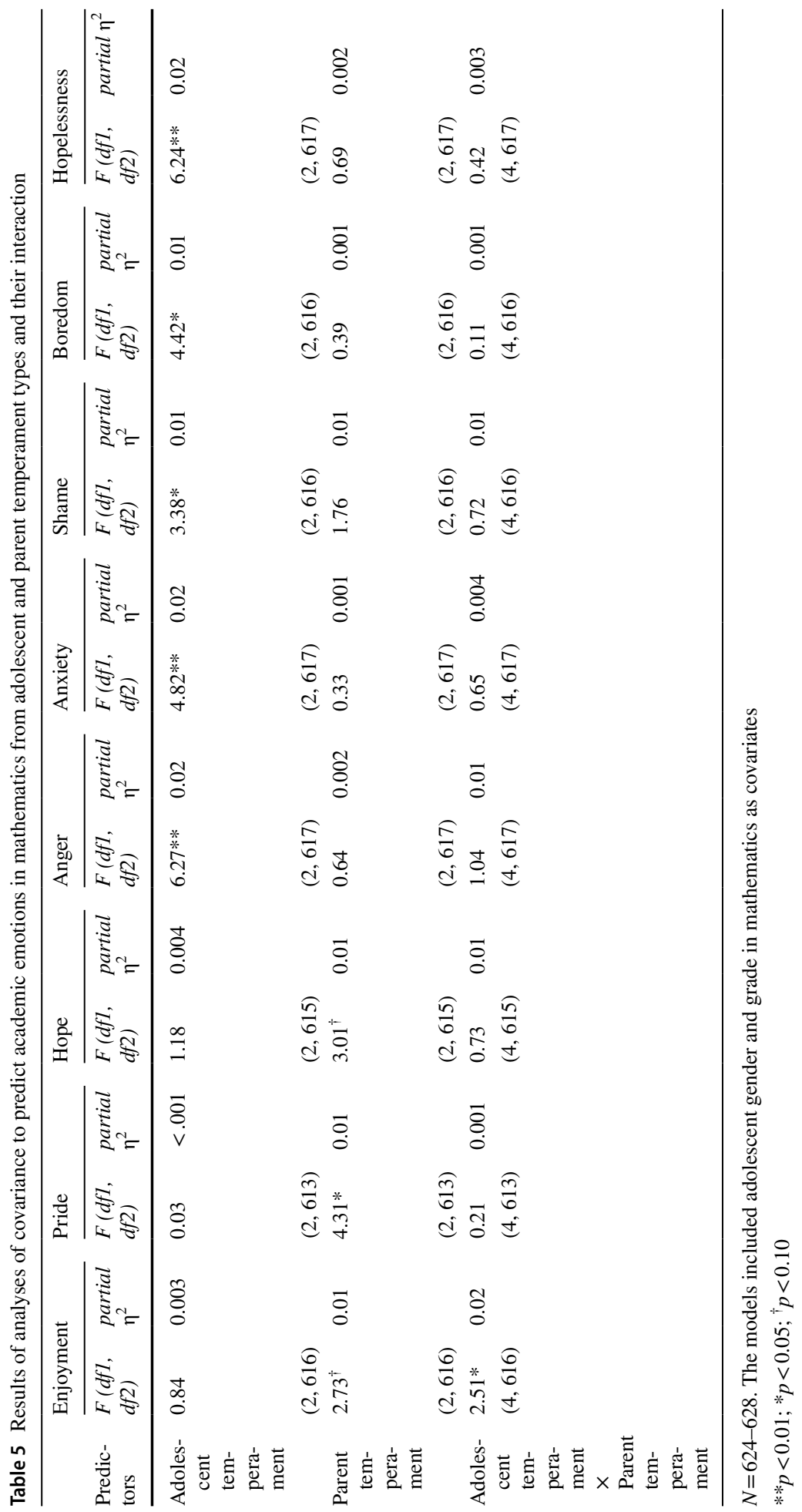


mean) adolescents of undercontrolled parents reported lower shame in mathematics if their own temperament type was resilient than if it was undercontrolled. In contrast, adolescents with a poor grade in mathematics (one SD below the mean) and a resilient parent, reported higher hopelessness if their own temperament type was undercontrolled than if it was overcontrolled or resilient. No interaction effects were found in anger, anxiety, or boredom in mathematics.

\section{Discussion}

In the present study, we examined the unique and interactive effects of adolescents' and parents' temperament types on adolescents' academic emotions in mathematics and literacy. The results showed that adolescents' temperament type was significantly related to their negative academic emotions: in both subjects, adolescents with an undercontrolled temperament reported more anger compared to adolescents with a resilient or overcontrolled temperament, and more anxiety, shame, and hopelessness compared to resilient adolescents. In mathematics, the undercontrolled adolescents also reported more boredom than adolescents with a resilient or overcontrolled temperament. The temperament type of the parent was found to have an effect on adolescents' positive emotions: Adolescents of resilient parents reported higher pride in mathematics than adolescents of undercontrolled or overcontrolled parents, and they also reported higher hope in mathematics than adolescents of overcontrolled parents. Overcontrolled adolescents benefited from having a parent with a resilient or overcontrolled temperament by reporting higher enjoyment of mathematics and literacy in comparison to overcontrolled adolescents with an undercontrolled parent.

\section{Adolescent Temperament and Academic Emotions}

The first aim of our study was to investigate to what extent adolescent temperament type was related to the academic emotions they report in mathematics and literacy. The results regarding positive emotions showed that adolescent temperament type was not related to any of the reported positive emotions (enjoyment, pride, and hope) in either subject. In contrast, adolescents' temperament type was found to play a significant role in their negative emotions in both subjects: adolescents with an undercontrolled temperament type reported more anxiety, shame, and hopelessness than resilient adolescents, as well as more anger than both resilient and overcontrolled adolescents. Regarding boredom, undercontrolled adolescents reported significantly higher boredom than resilient and overcontrolled adolescents in mathematics but not in literacy.

The findings supported our hypothesis concerning undercontrolled adolescents reporting the highest levels of anger, anxiety, hopelessness, and shame in both school subjects, and differing in these emotions especially from the resilient temperament type. Because of the below-average amount of effortful control and above-average level of negative emotionality, the undercontrolled type may be more prone to experiencing intense negative academic emotions (Lehikoinen et al. 2019; Lengua 2006; Lengua and Long 2002; Thompson et al. 2014). Moreover, the undercontrolled type may also tend to perceive situations as threatening and use less adaptive coping skills in regulating stress and anxiety in learning situations (Lengua and Long 2002; Thompson et al. 2014). Consequently, the undercontrolled temperament type may both be prone to experiencing more negative academic emotions, but may also have a lower ability to regulate these emotions compared to 
adolescents with higher effortful control and lower negative affectivity (i.e., resilient and overcontrolled adolescents).

Our expectation concerning the negative emotions of overcontrolled adolescents was partially confirmed. We expected the overcontrolled temperament type to show particularly high amounts of passive forms of negative emotions (boredom, hopelessness, and anxiety) because of their below-average level of extraversion and average level of effortful control with the possibility of emotion over-regulation and internalising problems (Robins et al. 1996; van Leeuwen et al. 2004). Our findings showed that overcontrolled adolescents reported the second to highest levels of hopelessness, boredom, and anxiety (as well as other negative emotions), but they did not significantly differ from the other adolescents. Consequently, the overcontrolled type appeared to have an average level of emotion regulation not so different from either of the other two groups. They probably benefited from having an average level of effortful control and thus being able to regulate their negative emotional reactions as well as resilient adolescents (Lengua and Long 2002; Thompson et al. 2014). On the other hand, because of their average level of negative affectivity, overcontrolled adolescents may be as prone to negative emotions as undercontrolled adolescents (Lehikoinen et al. 2019; Lengua and Long 2002). An additional explanation of overcontrolled adolescents' average levels of negative emotions could also be the possibility of social desirability. The overcontrolled type has been described as having lower social self-esteem (Asendorpf et al. 2001), as well as being obedient (Asendorpf and van Aken 1999) and dependent on the approval of others (Robins et al. 1996). It is possible that the overcontrolled type may be inclined to please when answering questionnaires, and therefore may not truthfully report negative academic emotions.

Finally, contrary to our expectations, no statistically significant differences were found between the adolescent temperament types in positive emotions. We had expected the resilient temperament type to report more positive academic emotions compared to the other types because of their low negative affectivity and high effortful control. As this assumption was not supported by the findings, the differences between positive and negative academic emotions need to be further investigated. It is possible that the arousal of positive emotions is more related to situation-specific factors such as students' daily mood or level of interest in the topic, whereas negative emotions relate more closely to dispositional factors such as students' typical way of reacting in stressful or unpleasant situations.

\section{Goodness-of-Fit between Parents' and Adolescents' Temperaments and Adolescents' Academic Emotions}

The second aim of our study was to investigate to what extent parents' temperament uniquely and in interaction with adolescent temperament contributes to adolescents' academic emotions. The findings showed, first, that adolescents of resilient parents reported more feelings of pride in mathematics than did adolescents of under- or overcontrolled parents, and they reported more feelings of hope in mathematics compared to adolescents with overcontrolled parents. Parents can influence adolescents' academic emotions through how they support adolescents' learning and communicate their values and expectations to the adolescents (Pekrun 2006). Because of their relatively high extraversion and low negative affectivity, parents with a resilient temperament may be more open to experiencing and expressing positive emotions (cf. Jaffe et al. 2010), which may also mean that resilient parents are prone to giving positive feedback and praising their adolescents for their effort and performance at school. This, in turn, could result in the adolescents' heightened sense of 
pride and hope in mathematics compared to adolescents whose parents do not express their positive emotions as openly.

Concerning the interactive effects of adolescent and parent temperaments, the only found effects showed that overcontrolled adolescents with an undercontrolled parent reported less enjoyment of mathematics and literacy compared to overcontrolled adolescents with a resilient parent (in both subjects) or an overcontrolled parent (literacy only). In other words, adolescents who themselves had low extraversion and average levels of effortful control and negative affectivity enjoyed learning less if their parents had an opposite type of temperament. In contrast, overcontrolled adolescents benefited from having a parent with a temperament more similar to their own temperament. According to the goodness-of-fit theory (Thomas and Chess 1977), a parent's understanding and respect towards an adolescent's temperamental characteristics influence the goodness-of-fit of the parent-adolescent relationship. Parents may understand adolescents' characteristics better if these are equivalent to the parents' own way of reacting. Consequently, since undercontrolled parents themselves are higher in extraversion and have low effortful control, it may be difficult for them to identify with an overcontrolled adolescent who has low extraversion and higher effortful control. This poorness-of-fit can further influence how the parents interact with the adolescents, express their positive emotions, and support the adolescents in their emotion regulation.

Apart from the above-discussed effects in positive academic emotions, parent temperament had no other unique or interactive effects with adolescent temperament. However, our additional analyses concerning the moderating role of literacy and math grades suggest that students' school performance may contribute to the parent-adolescent interaction and resulting academic emotions. For example, having a resilient parent was most beneficial for low-performing adolescents in terms of positive academic emotions, indicating that resilient parents may be more sensitive to their adolescents' struggles with learning and may succeed in providing them with support and encouragement that boost the adolescents' positive affect at school despite their difficulties. However, more research is needed to further understand the dynamics explaining these associations, such as the contribution of the adolescent-parent relationship to adolescents' control and value beliefs at different skill levels.

\section{Strengths, Limitations, and Future Directions}

One of the strengths of our study was that we examined the role of not only adolescents' own but also their parents' temperament types in adolescents' academic emotions. The goodness-of-fit between adolescents' and parents' temperaments has rarely been studied this way, and particularly not in relation to adolescents' emotions in the school context. Furthermore, instead of examining the sole effects of separate temperament traits, we used a person-oriented approach to identify temperament types among adolescents and their parents, which helps us to understand how different combinations of temperamental reactivity and regulation are related to academic emotions. Finally, although the found effects were rather small, they gain more credibility from the fact that we used a relatively large community sample of early adolescents and their parents.

The study also has limitations that need to be considered when interpreting the results. First, parent ratings were used as the basis for both adolescents' and parents' temperament types. Parents' own characteristics may have influenced how they perceived their child's temperament, and consequently, in future studies it is important to consider using 
also other informants, such as teachers or the adolescents themselves. A second limitation relates to the reliability of the academic emotions scale. In particular, the reliabilities of anger in literacy and mathematics were rather low, which can reduce the reliability of the results. Third, as our study focused on one age cohort in the Finnish school context, more heterogenous samples should be investigated in future studies, to generalise the results to other age groups and cultural contexts. Finally, as the additional analyses suggested that the found associations may be further moderated by students' performance level, the complex dynamics of temperament, skill level, and emotions should be further investigated by also considering, for example, the role of students' self-concepts of ability.

\section{Conclusions and Practical Implications}

Our research provides new knowledge about adolescent and parent temperaments and their relation to early adolescents' academic emotions. Overall, our results revealed three interesting contrasts in terms of the role of adolescent and parent temperaments and the subjectspecificity and valence of academic emotions. First, the findings showed that adolescent temperament type played a significantly larger role in academic emotions than did their parents' temperament type. Second, adolescents' temperament was associated with their experiences of negative emotions, whereas parent temperament had significant effects only on adolescents' positive emotions. Third, the found associations regarding the role of temperament were somewhat stronger in mathematics than in literacy. These contrasts should be further investigated in future studies.

As the findings of our study showed that adolescents' temperament was related to their experiences of academic emotions, it is important to pay attention to students' individual ways of reacting and experiencing emotions in learning situations. For example, students with an undercontrolled temperament type may be more prone to experiencing negative academic emotions. It is important to recognise and pay attention to this type of students, so that they could be better supported in their emotion regulation. In light of the results, it is also important to increase teachers' and parents' awareness of the role of temperament in adolescents' emotional experiences at school, in order to guarantee an individually supportive growth and learning environment for all students.

Funding Open access funding provided by University of Eastern Finland (UEF) including Kuopio University Hospital. The research was supported by the Academy of Finland (Grant Numbers 266851 and 294970).

Access to the Data The data analysed in this study are available from the corresponding author upon reasonable request. The corresponding author takes responsibility for the integrity and accuracy of the data analysis.

Open Access This article is licensed under a Creative Commons Attribution 4.0 International License, which permits use, sharing, adaptation, distribution and reproduction in any medium or format, as long as you give appropriate credit to the original author(s) and the source, provide a link to the Creative Commons licence, and indicate if changes were made. The images or other third party material in this article are included in the article's Creative Commons licence, unless indicated otherwise in a credit line to the material. If material is not included in the article's Creative Commons licence and your intended use is not permitted by statutory regulation or exceeds the permitted use, you will need to obtain permission directly from the copyright holder. To view a copy of this licence, visit http://creativecommons.org/licenses/by/4.0/. 


\section{References}

Ahonen, T., \& Kiuru, N. (2013-2017). The Stairway study-From primary school to lower secondary school [Unpublished dataset]. University of Jyväskylä, Finland.

Asendorpf, J. B., \& van Aken, M. A. G. (1999). Resilient, overcontrolled, and undercontrolled personality prototypes in childhood: replicability, predictive power, and the trait-type issue. Journal of Personality and Social Psychology, 77, 815-831. https://doi.org/10.1037/0022-3514.77.4.815

Asendorpf, J. B., Borkenau, P., Ostendorf, F., \& van Aken, M. A. G. (2001). Carving personality description at its joints: confirmation of three replicable personality prototypes for both children and adults. European Journal of Personality, 15, 169-198. https://doi.org/10.1002/per.408

Capaldi, D. M., \& Rothbart, M. K. (1992). Development and validation of an early adolescent temperament measure. Journal of Early Adolescence, 12, 153-173. https://doi.org/10.1177/0272431692 012002002

Ellis, L. K., \& Rothbart, M. K. (2001). Revision of the Early Adolescent Temperament Questionnaire. Poster presented at the 2001 Biennial Meeting of the Society for Research in Child Development, Minneapolis, Minnesota. Retrieved from: https://research.bowdoin.edu/rothbart-temperament-quest ionnaires/files/2016/09/lesa-ellis-srcd-poster-reprint.pdf

Evans, D. E., \& Rothbart, M. K. (2007). Developing a model for adult temperament. Journal of Research in Personality, 41, 868-888. https://doi.org/10.1016/j.jrp.2006.11.002

Flook, L., \& Fuligni, A. J. (2008). Family and school spillover in adolescents' daily lives. Child Development, 79, 776-787. https://doi.org/10.1111/j.1467-8624.2008.01157.x

Hart, D., Burock, D., London, B., Atkins, R., \& Bonilla-Santiago, G. (2005). The relation of personality types to physiological, behavioural and cognitive processes. European Journal of Personality, 19, 391-407. https://doi.org/10.1002/per.547

Hirvonen, R., Väänänen, J., Aunola, K., Ahonen, T., \& Kiuru, N. (2018). Adolescents' and mothers' temperament types and their roles in early adolescents' socioemotional functioning. International Journal of Behavioral Development, 42, 453-463. https://doi.org/10.1177/0165025417729223

Jaffe, M., Gullone, E., \& Hughes, E. K. (2010). The roles of temperamental dispositions and perceived parenting behaviours in the use of two emotion regulation strategies in late childhood. Journal of Applied Developmental Psychology, 31, 47-59. https://doi.org/10.1016/j.appdev.2009.07.008

Kiff, C. J., Lengua, L. J., \& Bush, N. R. (2011a). Temperament variation in sensitivity to parenting: predicting changes in depression and anxiety. Journal of Abnormal Child Psychology, 39, 1199-1212. https://doi.org/10.1007/s10802-011-9539-x

Kiff, C. J., Lengua, L. J., \& Zalewski, M. (2011b). Nature and nurturing: parenting in the context of child temperament. Clinical Child and Family Psychology Review, 13, 251-301. https://doi.org/10.1007/ s10567-011-0093-4

Lehikoinen, A., Ranta-Nilkku, E., Mikkonen, J., Kaartinen, J., Penttonen, M., Ahonen, T., \& Kiuru, N. (2019). The role of adolescents' temperament in their positive and negative emotions as well as in psychophysiological reactions during achievement situations. Learning and Individual Differences, 69, 116-128. https://doi.org/10.1016/j.lindif.2018.11.004

Lengua, L. J. (2006). Growth in temperament and parenting as predictors of adjustment during children's transition to adolescence. Developmental Psychology, 42, 819-832. https://doi. org/10.1037/0012-1649.42.5.819

Lengua, L. J., \& Long, A. C. (2002). The role of emotionality and self-regulation in the appraisalscoping process: tests of direct and moderating effects. Applied Developmental Psychology, 23, 471-493. https://doi.org/10.1016/S0193-3973(02)00129-6

Lerner, J. V., \& Lerner, R. M. (1994). Explorations of the goodness-of-fit model in early adolescence. In W. B. Carey \& S. C. McDevitt (Eds.), Prevention and early intervention: Individual differences as risk factors for the mental health of children: A festschrift for Stella Chess and Alexander Thomas (pp. 161-169). New York, NY: Brunner/Mazel.

Mandara, J. (2003). The typological approach in child and family psychology: a review of theory, methods, and research. Clinical Child and Family Psychology Review, 6, 129-146. https://doi. org/10.1023/A: 1023734627624

Official Statistics of Finland. (2018a). Educational structure of population (e-publication). Helsinki, Finland: Statistics Finland. Retrieved from http://www.stat.fi/til/vkour/2014/vkour _2014_2015-11-05_tie_001_en.html

Official Statistics of Finland. (2018b). Families. Appendix Table 3: Families with underage children by type in 1950-2014 (e-publication). Helsinki, Finland: Statistics Finland. Retrieved from http:// www.stat.fi/til/perh/2014/perh_2014_2015-05-28_tau_003_en.html 
Official Statistics of Finland (2020). Population structure (e-publication). Helsinki, Finland: Statistics Finland. Retrieved from https://www.stat.fi/til/vaerak/tau_en.html

Oldehinkel, A. J., Veenstra, R., Ormel, J., de Winter, A. F., \& Verhulst, F. C. (2006). Temperament, parenting, and depressive symptoms in a population sample of preadolescents. Journal of Child Psychology \& Psychiatry, 47, 684-695. https://doi.org/10.1111/j.1469-7610.2005.01535.x

Pekrun, R. (2006). The control-value theory of achievement emotions: assumptions, corollaries, and implications for educational research and practice. Educational Psychology Review, 18, 315-341. https:// doi.org/10.1007/s10648-006-9029-9

Pekrun, R., Goetz, T., Frenzel, A. C., Barchfeld, P., \& Perry, R. P. (2011). Measuring emotions in students' learning and performance: the achievement emotions questionnaire (AEQ). Contemporary Educational Psychology, 36, 36-48. https://doi.org/10.1016/j.cedpsych.2010.10.002

Pekrun, R., Goetz, T., Titz, W., \& Perry, R. P. (2002). Academic emotions in students' self-regulated learning and achievement: a program of quantitative and qualitative research. Educational Psychologist, 37, 91-106. https://doi.org/10.1207/S15326985EP3702_4

Pekrun, R., \& Perry, R. P. (2014). Control-value theory of achievement emotions. In R. Pekrun \& L. Linnenbrink-Garcia (Eds.), International Handbook of Emotions in Education (pp. 120-142). New York, NY: Routledge.

Ramsden, S. R., \& Hubbard, J. A. (2002). Family expressiveness and parental emotion coaching: their role in children's emotion regulation and aggression. Journal of Abnormal Child Psychology, 30, 657-667. https://doi.org/10.1023/A:1020819915881

Rettew, D., Stanger, C., McKee, L., Doyle, A., \& Hudziak, J. (2006). Interactions between child and parent temperament and child behavior problems. Comprehensive Psychiatry, 47, 412-420. https://doi. org/10.1016/j.comppsych.2005.12.008

Robins, R., John, O., Caspi, A., Moffitt, T., \& Stouthamer-Loeber, M. (1996). Resilient, overcontrolled and undercontrolled boys: three replicable personality types. Journal of Personality and Social Psychology, 70, 157-171. https://doi.org/10.1037/0022-3514.70.1.157

Rothbart, M. K., Ahadi, S., \& Evans, D. (2000). Temperament and personality: origins and outcomes. Journal of Personality and Social Psychology, 78, 122-135. https://doi.org/10.1037/0022-3514.78.1.122

Rothbart, M. K., Ahadi, S. A., Hershey, K. L., \& Fisher, P. (2001). Investigations of temperament at three to seven years: The Children's Behavior Questionnaire. Child Development, 72, 1394-1408. https://doi. org/10.1111/1467-8624.00355

Rothbart, M. K., \& Bates, J. E. (2007). Temperament. In W. Damon, R. M. Lerner, \& N. Eisenberg (Eds.), Handbook of Child Psychology Vol. 3 (6th ed., pp. 99-166). New York: Wiley. doi:https://doi. org/10.1002/9780470147658.chpsy0303

Shiner, R. L., Buss, K. A., McClowry, S. G., Putnam, S. P., Saudino, K. J., Zentner, M. (2012). What is temperament now? Assessing progress in temperament research on the twenty-fifth anniversary of Goldsmith. Child Development Perspectives, 6, 436-444. https://doi.org/10.1111/j.1750-8606.2012.00254 .X

Soric, I., Penezic, Z., \& Buric, I. (2013). Big Five personality traits, cognitive appraisals and emotion regulation strategies as predictors of achievement emotions. Psychological Topics, 22, 325-349.

Thomas, A., \& Chess, S. (1977). Temperament and development. New York: Brunner/Mazel.

Thompson, S. F., Zalewski, M., \& Lengua, L. J. (2014). Appraisal and coping styles account for the effects of temperament on pre-adolescent adjustment. Australian Journal of Psychology, 66, 122-129. https:// doi.org/10.1111/ajpy.12048

Timmons, A. C., \& Margolin, G. (2015). Family conflict, mood, and adolescents' daily school problems: moderating roles of internalizing and externalizing symptoms. Child Development, 86, 241-258. https ://doi.org/10.1111/cdev.12300

van Leeuwen, K., de Fruyt, F., \& Mervielde, I. (2004). A longitudinal study of the utility of the resilient, overcontrolled, and undercontrolled personality types as predictors of children's and adolescents' problem behaviour. International Journal of Behavioural Development, 28, 210-220. https://doi. org/10.1080/01650250344000424

Yap, M. B. H., Allen, N. B., \& Sheeber, L. (2007). Using an emotion regulation framework to understand the role of temperament and family processes in risk for adolescent depressive disorders. Clinical Child \& Family Psychology Review, 10, 180-196. https://doi.org/10.1007/s10567-006-0014-0

Publisher's Note Springer Nature remains neutral with regard to jurisdictional claims in published maps and institutional affiliations. 


\section{Affiliations}

Pinja Lahdelma ${ }^{1} \cdot$ Maria Tolonen $^{1} \cdot$ Noona Kiuru ${ }^{1} \cdot$ Riikka Hirvonen $^{2}$

$\triangle$ Riikka Hirvonen

riikka.hirvonen@uef.fi

1 Department of Psychology, University of Jyväskylä, Jyväskylä, Finland

2 School of Applied Educational Science and Teacher Education, University of Eastern Finland, P.O. Box 111, 80101 Joensuu, Finland 